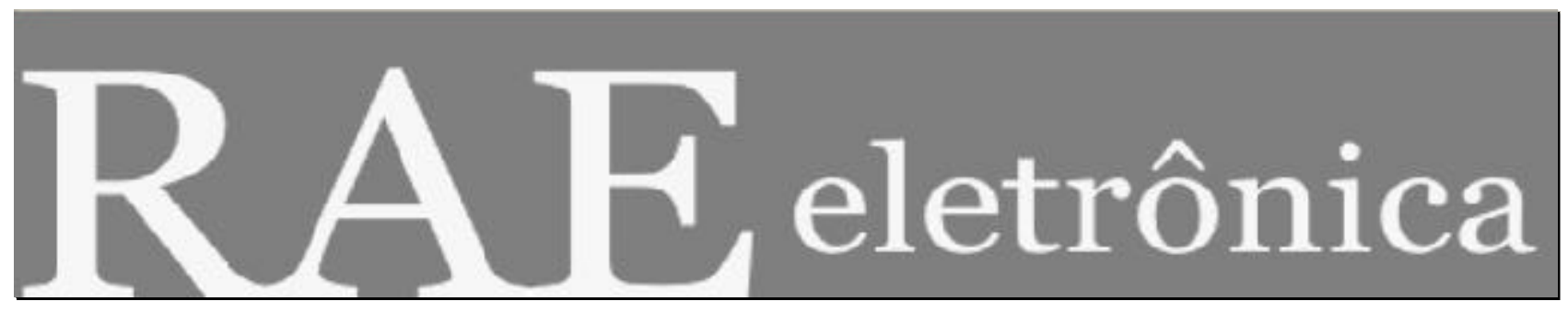

\title{
COMO CONSTRUIR UMA ESTRATÉGIA DE DESENVOLVIMENTO?
}

Por:

\section{Cecília Olivieri - FGV-EAESP}

RAE-eletrônica, v. 4, n. 2, Resenha 1, jul./dez. 2005

http://www.rae.com.br/eletronica/index.cfm?FuseAction=Artigo\&ID=3537\&Secao=RESENHAS \&Vol ume $=4 \&$ Numero $=2 \& A n=2005$

CCopyright, 2005, RAE-eletrônica. Todos os direitos, inclusive de tradução, são reservados. É permitido citar parte de artigos sem autorização prévia desde que seja identificada a fonte. A reprodução total de artigos é proibida. Os artigos só devem ser usados para uso pessoal e nãocomercial. Em caso de dúvidas, consulte a redação: raeredacao@fgvsp.br.

A RAE-eletrônica é a revista on- line da FGV-EAESP, totalmente aberta e criada com o objetivo de agilizar a veiculação de trabalhos inéditos. Lançada em janeiro de 2002, com perfil acadêmico, é dedicada a professores, pesquisadores e estudantes. Para mais informações consulte o site www.rae.com.br/eletronica.

\section{RAE-eletrônica}

ISSN 1676-5648

(C2005 Fundação Getulio Vargas - Escola de Administração de Empresas de São Paulo.

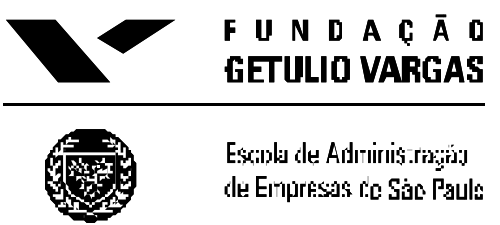




\title{
COMO CONSTRUIR UMA ESTRATÉGIA DE DESENVOLVIMENTO?
}

\author{
Por: \\ Cecília Olivieri \\ Doutoranda em Administração Pública e Governo na FGV-EAESP \\ E-mail: ceciliaolivieri@gvmail.br
}

\section{CHUTANDO A ESCADA: A ESTRATÉGIA DO DESEN VOLVIMENTO EM PERSPECTIVA HISTÓRICA}

De Ha-Joon Chang

São Paulo: Editora Unesp, 2004. 265 p.

Como promover o desenvolvimento econômico e a democracia em países pobres ou pouco desenvolvidos? Essa questão interessa não apenas a governos comprometidos com o desenvolvimento de suas nações, mas também às elites econômicas e empresariais, coadjuvantes e beneficiárias dos processos de desenvolvimento econômico e de democratização. Em seu livro, Ha-Joo Chang pretende responder a essa questão e mostrar que as instituições internacionais, como o Banco Mundial e o FMI, não têm a resposta correta. A partir de uma ampla revisão histórica do processo de desenvolvimento econômico e institucional dos países hoje considerados ricos ou desenvolvidos, o autor mostra que as políticas atualmente prescritas por essas instituições aos países em desenvolvimento contrariam as lições do passado, impedindo esses países de "subirem a escada" em direção ao mundo desenvolvido.

As "boas políticas" - estabilidade monetária, equilíbrio fiscal, livre comércio - e as "boas instituições" - banco central autônomo, judiciário independente, eleições livres, burocracia weberiana, proteção legal da propriedade - estão equivocadas, em parte, por falta de informação, e, em parte, por má-fé dos países desenvolvidos. Para resolver a primeira falha, Chang empreende uma revisão da história econômica dos países desenvolvidos, mostrando que esses países adotaram, quando ainda eram economias em desenvolvimento, políticas que hoje condenam e que seus mais influentes intelectuais e think tanks desaconselham. O autor também mostra que muitas das instituições políticas e econômicas hoje consideradas indispensáveis para o desenvolvimento são, na verdade, conseqüência desse desenvolvimento. Essas instituições foram construídas em um processo histórico longo e politicamente conflituoso, e esse caminho árduo de construção institucional não pode ser completamente evitado pelos países em desenvolvimento através do aprendizado ou da cópia, ignorando a cultura e a tradição desses países. Sobre a segunda falha, a crítica é pouco explícita no texto, mas está clara desde o título do livro, que acusa os países ricos de "chutarem a escada", ou seja, de tirarem do alcance dos países em desenvolvimento a fórmula de seu sucesso, por meio das pressões políticas e das prescrições econômicas impostas a estes pelas instituições internacionais.

Em uma análise não muito profunda, mas bastante ampla, que perpassa diversos países europeus, norte-americanos, asiáticos, e diversas políticas industriais, comerciais e tecnológicas, o autor mostra como os países hoje desenvolvidos adotaram, no passado, políticas econômicas que se 
mostraram muito eficientes. Entre elas, o financiamento público às indústrias nascentes, garantia de monopólios e políticas tarifárias protecionistas, ou seja, o oposto em relação ao mainstream liberal prescrito atualmente aos países em desenvolvimento. $\mathrm{O}$ autor derruba mitos arraigados, como, por exemplo, a fama de liberais puros e inatos da Inglaterra e dos Estados Unidos. Naqueles países, o livre comércio só foi praticado quando suas economias apresentaram condições de concorrer em posição vantajosa no mercado internacional.

Chang mostra como os países atualmente desenvolvidos se encontravam, quando em desenvolvimento, em um nível institucional mais baixo que os países hoje em desenvolvimento. Por exemplo, em relação a uma das principais instituições democráticas, o voto, nenhum dos países hoje desenvolvidos concedeu sufrágio universal antes de alcançar uma renda per capta de US\$2.000, enquanto a maioria dos países atualmente em desenvolvimento concedeu-o em nível de renda mais baixo. Chang mostra, ainda, que os países hoje desenvolvidos demoraram muitas décadas para estabelecer uma Administração Pública com um sistema de mérito, bem como para conseguir implantar e fazer cumprir institutos jurídicos hoje considerados triviais, como a responsabilidade limitada dos sócios. Na Inglaterra, hoje um exemplo do sistema de mérito na Administração Pública, podia-se encontrar, até a primeira metade do século XIX, sinecuras e ministérios que não respondiam ao Parlamento, atuando como se fossem entidades privadas. Tratando do tema hoje conhecido como governança empresarial, responsabilidade limitada foi vista, durante séculos, como um desserviço à economia, que levaria, nas palavras de Adam Smith citadas por Chang, "os administradores à vadiagem". De acordo com essa visão, a limitação da responsabilidade dos sócios poderia estimular os administradores e sócios a assumirem riscos excessivos, uma vez que seu patrimônio pessoal estaria a salvo das conseqüências de uma eventual falência. A experiência histórica mostrou que essa interpretação estava errada, e prevaleceu a visão dos benefícios desse instituto para a expansão dos investimentos.

O autor também mostra que os países hoje desenvolvidos prescindiram de muitas dessas instituições para se tornarem ricos e que só as adotaram quando já tinham condições de suportar seus custos econômicos. Por exemplo, as instituições de bem-estar social e a regulamentação sobre as jornadas e a segurança no trabalho não existiam ou eram absolutamente ineficazes nos países que lideravam o processo de desenvolvimento industrial durante o século XIX. Além disso, os países atualmente em desenvolvimento não precisam e não devem despender recursos escassos na construção de instituições que podem mostrar-se dispendiosas e inúteis. Chang critica o caso da Mongólia, onde o governo norte-americano, após a derrocada do socialismo, gastou fortunas para treinar jovens mongóis como corretores da Bolsa, ao invés de gastálas com coisas bem mais úteis ao desenvolvimento desse país. Mas o autor não nega, entretanto, que o aprendizado institucional seja desejável, como uma forma de reduzir o tempo de construção das instituições nos países em desenvolvimento, nem que, em parte, o aprimoramento das instituições possa ajudar a promover o desenvolvimento econômico.

Analiticamente, o ponto forte da obra de Chang é deixar claras a importância e a precisão do enfoque histórico e institucional. Recolocando a ênfase na historicidade, no papel da conjuntura social e dos conflitos políticos, o autor empreende uma análise estimulante sobre o desenvolvimento econômico e suas imbricadas relações com o desenvolvimento social, político e institucional.

Para leitores brasileiros, o livro se torna ainda mais instigante pela atualidade do tema. Boa parte dos debates políticos e intelectuais das últimas décadas têm girado em torno da questão do desenvolvimento econômico do país, o último deles sendo a disputa sobre a avaliação do legado varguista. A par disso, a grande influência das instituições internacionais na condução de nossas 
políticas internas, também tema de disputas ácidas, nos torna mais aptos a fazer a pergunta que Chang deixa implícita: a quem interessam as políticas que chutam a nossa escada?

Outra pergunta, talvez mais importante, também não é feita por Chang: como construir uma escada, ou seja, como definir quais passos ou caminhos adotar para alcançar o desenvolvimento? Como o próprio autor admite, não basta conhecer a experiência dos países que chegaram lá para ter a resposta, pois muitos dos passos adotados no passado pelos países atualmente desenvolvidos não estão mais disponíveis para os países em desenvolvimento. E a indisponibilidade não é causada apenas pelos obstáculos impostos pelas instituições internacionais, mas pelas condições históricas diversas e pela conjuntura política e institucional. A pergunta mais difícil e mais necessária é, então: conhecendo as lições do passado e conhecendo as diferenças entre aquela realidade e a atual, como construir a nossa escada? 